Review article

\title{
CURRENT CONCEPTS OF RESPIRATORY INSUFFICIENCY SYNDROMES AFTER FRACTURE
}

\author{
C. M. Robinson \\ From the Royal Infirmary of Edinburgh, Scotland
}

Episodes of hypoxia and acute respiratory insufficiency often occur after orthopaedic trauma. ${ }^{1,2}$ Most patients who have sustained a major injury to the pelvis or a long bone are monitored using pulse oximetry, and the onset of respiratory symptoms is usually presaged by episodes of desaturation. ${ }^{3}$ The reason for the hypoxia is often apparent after careful clinical assessment (Table I), and it is usually reversible by the administration of oxygen and treatment of the precipitating cause. In a few patients, however, the cause of the deterioration in respiratory function is not obvious or easily correctible and demands more sophisticated investigation. In these, the onset of hypoxia may be associated simultaneously with the development of dysfunction of other vital organs. The terms fat embolus syndrome (FES) and acute (or adult) respiratory distress syndrome (ARDS) have both been used to describe this pattern of unexplained refractory hypoxaemia.

The fat embolus syndrome (FES) was first described in $1862,{ }^{4}$ although much of the research into this condition was carried out between 30 and 40 years ago and coincided with the recognition of ARDS as a discrete entity in the critically-ill patient. ${ }^{5}$ The considerable overlap, and the lack of concrete definitions, have dictated that both terms have continued to be used almost interchangeably. The expression 'fat embolism' is often loosely employed to describe both the intravasation of fat into the circulation (fat embolisation or FE) and the specific cluster of respiratory, dermatological and neurological symptoms and signs which occur in some patients after injury (FES). These should not be confused, because they do not necessarily always occur in tandem. ARDS is used to describe the respiratory failure associated with evidence of multiple-organ dysfunction, which occurs in patients after high-energy injury.

There have been much speculation and debate about the pathogenesis of these syndromes, and their inter-relationship. Both share common clinical features and may be produced by a variety of non-traumatic causes. Most of the

C. M. Robinson, BMedSci, FRCS Ed (Orth), Senior Lecturer and Consultant Orthopaedic Surgeon

Edinburgh Orthopaedic Trauma Unit, Royal Infirmary of Edinburgh, Lauriston Place, Edinburgh EH3 9YW, UK.

(C2001 British Editorial Society of Bone and Joint Surgery 0301-620X/01/612440 \$2.00

J Bone Joint Surg [Br] 2001;83-B:781-91. recent discussion has taken place in specialties such as intensive care and respiratory medicine, molecular biology and in immunology in which there have been considerable advances in our understanding of the pathological basis of ARDS. Clinicians in these fields are also involved increasingly in the medical management of patients who develop these complications and the role of the orthopaedic trauma surgeon is in danger of being marginalised to that of a technician.

Despite the increasing sophistication of medical and anaesthetic management, however, there is ample evidence to indicate that the early treatment of fractures in a multiply-injured patient has a significant effect on the risk of the subsequent development of respiratory complications. A multidisciplinary approach, with continued input from the orthopaedic trauma surgeon, is therefore vital in the early care of these patients.

\section{Current theories of the pathophysiological} mechanisms

Injury causes activation of cellular defence mechanisms and the elaboration of humoral and cell-surface mediators of inflammation and coagulation. ${ }^{1,6}$ These responses are protective, acting as a barrier against infection, removing damaged tissue and initiating repair. Recently, natural antiinflammatory mediators have also been described which modulate these processes. ${ }^{7}$ It is hypothesised that an imbalance may lead either to a generalised proinflammatory state (systemic inflammatory response syndrome or SIRS) which produces endothelial cell damage, increased microvascular permeability and interstitial oedema, or to suppression of inflammation and anergy (compensatory anti-inflammatory response syndrome or CARS) producing susceptibility to sepsis. ${ }^{8}$ This imbalance may be produced either by severe injury or as an idiosyncratic response by the individual. ${ }^{9}$

The clinical syndrome of ARDS is considered to be a local manifestation of SIRS. The lung is prominently targeted in the early stages, but if the patient survives, features of cardiac, gastrointestinal, renal, hepatic, haematological and cerebral failure become apparent, as part of the syndrome of multiple-organ dysfunction (MODS). Evidence of MODS is almost invariably found at post-mortem in patients who die from ARDS after 72 hours. ${ }^{10,11}$ 
Table I. Common underlying causes for arterial hypoxaemia after trauma

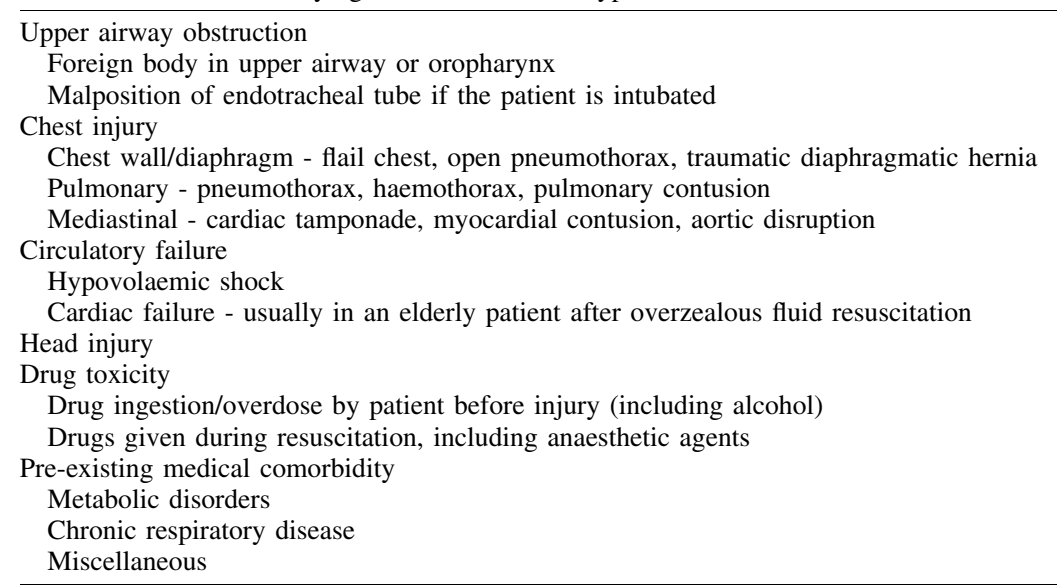

At present, we have incomplete knowledge of the complex series of inflammatory events which leads to ARDS after trauma, although the local release of cytokines, ${ }^{12}$ the complex interactions between platelets and circulating leucoytes with vascular endothelial cells, ${ }^{13}$ the extravasation and degranulation of neutrophils to produce toxic products, ${ }^{14}$ and the activation of neuroendocrine, complement, coagulative and fibrinolytic pathways, ${ }^{14,15}$ are certainly involved. The histological findings include microvascular occlusion from fibrin and platelet aggregates and interstitial leakage of protein- and neutrophil-rich fluid, leading to diffuse alveolar damage. ${ }^{16}$ Subsequently, proliferation of fibroblasts leads to fibrosis and the formation of a hyaline-like membrane if the patient survives. Detectable changes in the physiology of the lung include decreased functional residual capacity, decreased compliance and increased pulmonary vascular resistance. There is also evidence of pulmonary vascular shunting because of ventilation-perfusion mismatch, which is considered to be the major cause of the refractory hypoxaemia. ${ }^{17}$

Clarification of the factors which provoke the development of ARDS after trauma is of considerable interest since they could, potentially, be preventable. A severe proinflammatory response may be sufficient to precipitate ARDS soon after injury and sepsis is implicated after prolonged supportive care. It is also hypothesised that secondary events (or 'hits') after injury may also drive a patient with a primed inflammatory response towards ARDS. ${ }^{18}$ The clinical evidence for this is still unconvincing, but the theory is attractive, since it may help to explain why some trauma patients deteriorate after a latent period.

Significant secondary events may include episodes of hypoxia, circulatory imbalance (especially residual hypovolaemia), sepsis, blood transfusions, and other unknown factors. ${ }^{18}$ The timing and type of surgery for fractures may also constitute a modifiable secondary insult. ${ }^{19,20}$ From a pathophysiological viewpoint, the operation may provoke further activation of inflammatory pathways, blood loss, or episodes of tissue hypoperfusion/hypoxia. FE, produced either at the time of injury or during an operation (particularly if an intramedullary nailing technique is used), may also be a trigger for the development of ARDS.

Fat embolisation after fracture: is it important? There is strong circumstantial evidence that post-traumatic FE has a central role in the development of respiratory compromise. Fat can be detected in the lungs soon after fracture ${ }^{21,22}$ and may pass into the systemic circulation through pulmonary capillaries and shunts, ${ }^{21,22}$ or through a patent foramen ovale, $^{23}$ to produce the characteristic features of systemic embolisation.

The biological plausibility of fat as a major cause of post-traumatic respiratory insufficiency is supported by animal experiments in which intravenous injections of fat emulsions produced pathophysiological features similar to those of FES. ${ }^{24,25} \mathrm{FE}$ can also produce tissue damage by direct injury as a result of vascular occlusion, breakdown to toxic free-fatty acids, and by activation of platelets and the coagulative and fibrinolytic cascades. ${ }^{24,26,27}$

The intravasation of fat was seen as the major culprit in the pathogenesis of post-traumatic respiratory compromise in the 1960s, when much of this work was performed. It is now appreciated, however, that embolism occurs in over $90 \%$ of patients after fracture ${ }^{28}$ and invariably during reamed nailing of fractures. ${ }^{29}$ It is uncertain whether the degree of FE correlates with the severity of injury to the lung or the risk of ARDS, ${ }^{28,30}$ but only $1 \%$ to $5 \%$ of patients develop FES. ${ }^{21}$ Further studies in animal models have shown that intravascular fat appears to produce a negligible inflammatory response. ${ }^{27,31,32}$ The importance of fat as a cause of ARDS in the multiply-injured patient therefore remains in doubt. ${ }^{33}$ There is often ample evidence of other secondary triggers for ARDS after injury, ${ }^{34,35}$ and the role of FE is difficult to define.

The exact role of FE in the FES also deserves further scrutiny. Several of the features of the latter syndrome, 
including its 'sporadic' occurrence in patients after relatively minor injury, the systemic embolic features of cutaneous and central nervous involvement, and the occurrence of a fulminant form which leads to acute right ventricular failure and cardiovascular collapse, ${ }^{23}$ suggest that it may well be important. As with the mediators of ARDS, it is conceivable that FES may occur either from massive FE, particularly in the presence of a patent foramen ovale, or may represent an abnormal response of the individual to intravasation of fat. ${ }^{36}$

More recent work has provided evidence of important interactions between FE, the coagulative effect which it produces and the inflammatory response, further confirming the complexity of the pathogenic mechanisms involved. $^{15,37-39}$ Many of the minor features of FES are similar to those of SIRS and the pulmonary disease process is identical to ARDS. There may be a final common pathological pathway for both FES and ARDS (Fig. 1).

\section{Epidemiology of post-traumatic respiratory} compromise

The accurate estimation of the incidence of ARDS and FES in patients with fractures is difficult. Prospective studies with less stringent diagnostic criteria have reported higher levels than retrospective studies with rigorous diagnostic measures. There is considerable overlap between the two conditions and many patients who were thought to have FES in the 'preintensive care' era would now be considered to have ARDS. It is generally accepted that the incidence of these complications has decreased due to improvements in both the resuscitation and early treatment of fractures during the last 30 years.

The incidence of ARDS after major trauma is probably between $5 \%$ and $8 \%,{ }^{34,40}$ but is much lower after an isolated fracture. There is a 'biological gradient' of risk with increasing severity of injury. ${ }^{41}$ The incidence of FES after fracture is $0.5 \%$ to $5 \%,{ }^{42-44}$ although it is possible that this may only be the 'tip of the iceberg' with subclinical forms being more common than has been generally appreciated. $^{2}$ The incidence of FES has been noticed to increase with the severity of injury in some studies, ${ }^{42,45}$ whereas others have suggested that the condition is sporadic. ${ }^{46}$

Both conditions are commonest in young individuals with fractures of the pelvis or long bones in the leg, possibly because they are more commonly sustained in

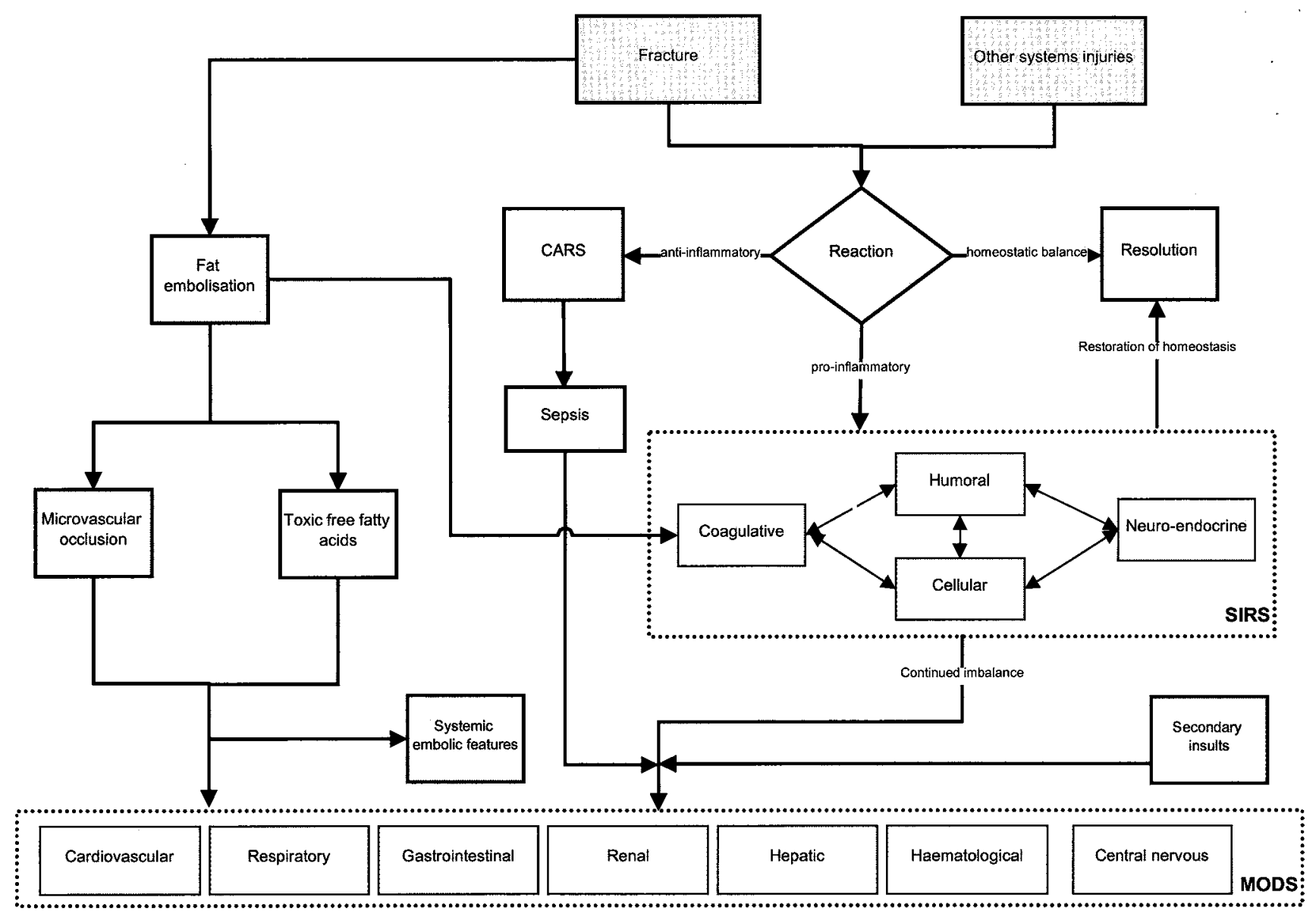

Fig. 1

Flow diagram showing the possible pathological mechanisms involved in post-traumatic respiratory compromise. 
Table II. Suggested framework for evaluation of patients with unexplained post-traumatic respiratory dysfunction

\begin{tabular}{|c|c|c|}
\hline Diagnostic criterion & ALI/ARDS & FES \\
\hline Injury severity & $\begin{array}{l}\text { Severe multiple-system injury (ISS }>18 \text { ) or } \\
\text { multiple fractures (a 'biological gradient' } \\
\text { of increased likelihood with increasing } \\
\text { severity of injury) }\end{array}$ & $\begin{array}{l}\text { Variable but often low-energy isolated injury ('sporadic } \\
\text { occurrence') }\end{array}$ \\
\hline Pulmonary involvement & $\begin{array}{l}\text { Three main diagnostic criteria: } 1 \text { ) bilateral } \\
\text { 'snowstorm' appearance on chest radiographs, } \\
\text { 2) absence of signs of cardiac failure, and } \\
\text { 3) } \mathrm{PaO}_{2} / \mathrm{FiO}_{2} \text { ratio }>26.7 \text { and }<40 \text { (ALI) or } \\
\mathrm{PaO}_{2} / \mathrm{FiO}_{2} \text { ratio }<26.7 \text { (ARDS) }\end{array}$ & Same diagnostic criteria as for ALI or ARDS \\
\hline Systemic inflammation & $\begin{array}{l}\text { Often present before signs of respiratory } \\
\text { involvement. Diagnosis of SIRS depends on } \\
\text { finding two or more of: } 1 \text { ) tachycardia }>90 \\
\text { beats } / \mathrm{min}, 2 \text { ) temperature }>38^{\circ} \mathrm{C} \text { or }<36^{\circ} \mathrm{C}, 3 \text { ) } \\
\text { respiratory rate }>20 \text { breaths } / \text { minute or } \\
\mathrm{PaCO}_{2} / \mathrm{FiO}_{2}<4.3 \mathrm{kPa} \text {, and } 4 \text { ) white blood } \\
\text { count }>12000 \text { cells } / \mathrm{mm}^{3} \text { or }>10 \% \text { immature } \\
\text { forms) }\end{array}$ & $\begin{array}{l}\text { Similar diagnostic criteria should now be used as for systemic } \\
\text { inflammation in ALI/ARDS ('classic' signs of FES } \\
\text { include tachycardia, increased respiratory rate, pyrexia and } \\
\text { raised ESR and may be similar in aetiology to SIRS) }\end{array}$ \\
\hline Other organ involvement & $\begin{array}{l}\text { Scoring of MODS: typically cardiovascular } \\
\text { (heart rate or mean arterial blood pressure), } \\
\text { respiratory }\left(\mathrm{PaO}_{2} / \mathrm{FiO}_{2}\right) \text { ratio), renal (urea } \\
\text { and creatinine levels or urine output over } \\
\text { 24-hour period), hepatic (bilirubin levels), } \\
\text { CNS (Glasgow Coma Scale), haematological } \\
\text { (platelet count, white blood count, prothrombin } \\
\text { time) }\end{array}$ & Similar scoring systems to MODS scores in ALI/ARDS \\
\hline Systemic embolism & $\begin{array}{l}\text { Typically absent: unable to elicit CNS signs if } \\
\text { the patient is anaesthetised and ventilated; } \\
\text { observe for signs of a petechial rash which may } \\
\text { suggest FE as a cause of ALI/ARDS }\end{array}$ & $\begin{array}{l}\text { Petechial rash on upper torso; CNS involvement includes acute } \\
\text { confusional state or any form of focal neurological deficit }\end{array}$ \\
\hline
\end{tabular}

high-energy injuries. They are uncommon in children and the elderly, although they may occur in patients with fractures of the hip.

\section{Clinical assessment}

FES and ARDS cannot in themselves be considered to be diagnoses. There is no single test or sign which is confirmatory and both describe clusters of clinical signs and abnormal investigations. Many of the 'major' and 'minor' criteria for FES, however, which were used in previous studies, ${ }^{47-50}$ now appear to be outdated or have been shown to be non-specific for the condition. An updated framework for the investigation and diagnosis of both conditions is shown in Table II and is discussed in more detail below.

Pulmonary compromise. The cardinal pulmonary signs of ARDS and FES are refractory hypoxaemia, not correctable by high-dose oxygen therapy (60\% to $100 \%)$, associated with the development of a characteristic 'snowstorm' appearance in both lung fields on chest radiography (Table II). The degree of respiratory compromise cannot be estimated by assessment of the arterial oxygen concentration alone, since this is dependent on the inspired oxygen concentration, whether administered by mask or ventilator. Correction is made by dividing the arterial oxygen concentration by the fractional inspired oxygen concentration to obtain the $\mathrm{PaO}_{2} / \mathrm{FiO}_{2}$ ratio. ${ }^{51}$ The diagnosis is established by a process of exclusion after all other remediable contrib- utory causes for respiratory failure have been eliminated (Table I). Diagnostic pitfalls include cardiac failure from the overzealous administration of fluid in attempts at resuscitation, which should be excluded by measuring pulmonary capillary wedge pressures, and the presence of diffuse pulmonary contusions, which are usually apparent immediately after the injury and are more pronounced in one lung field.

ARDS is best considered as a spectrum of disease and this is reflected by its subdivision into ARDS proper, and a less severe form of acute lung injury (ALI). ${ }^{52}$ The use of these two terms is appropriate after trauma since the degree of arterial hypoxaemia may initially be mild (Table II). Respiratory failure is also seen in $75 \%$ of patients with $\mathrm{FES}^{48}$ and is clinically indistinguishable from ALI/ARDS.

These definitions are more difficult to apply in patients receiving mechanical ventilation. Other more complex considerations including the duration of mechanical ventilation, the extravascular water volume of the lung, static compliance of the chest wall and the requirement for positive end-expiratory pressure have been described, although none has found general acceptance. ${ }^{52}$ More specialised diagnostic techniques, which may have an increasing role in the future, have been used experimentally, including examination of bronchoalveolar lavage fluid for inflammatory mediators ${ }^{53}$ or fat-laden macrophages, ${ }^{54}$ and the cytology of fluid retrieved from the pulmonary microvascular circulation. ${ }^{55}$ 
Other systemic features. Scoring systems for SIRS and MODS have been suggested using relatively simple diagnostic tools $^{11,56,57}$ (Table II). As with the lung, there is a spectrum of dysfunction of other solid organs and the diagnosis of MODS rests on exclusion of other underlying causes, including organ dysfunction from direct trauma during the original injury.

The classic 'early' signs of FES ${ }^{47-49}$ including tachycardia, increased respiratory rate and pyrexia, are similar to those of SIRS, and the 'minor' clinical signs of circulatory, renal and hepatic dysfunction seen in this condition are indistinguishable from MODS. A characteristic petechial rash is found in $60 \%$ of patients with $\mathrm{FES}^{48}$ and neurological features are encountered in over $80 \%,{ }^{58}$ including the development of an acute confusional state or a focal neurological deficit (Table II).

Much has been made of the 'latent period' before the onset of the clinical features of FES and ARDS. This cannot be seen as a specific diagnostic criterion since many patients develop signs immediately after injury. Similarly, the laboratory detection of evidence of FE in the blood, retina, urine or sputum and the development of anaemia, a raised ESR or thrombocytopenia, are non-specific features of FES. Specialist imaging techniques, including MRI and transcranial Doppler studies, have occasionally been useful, although their specificity is unknown. ${ }^{59,60}$

The clinical distinction of FES from ALI/ARDS. In the presence of multiple injuries (injury severity score (ISS) ${ }^{61}$ greater than 18), the clinicopathological features of FES and ALI/ARDS overlap to such an extent that absolute distinction is usually not possible. This is particularly so if the patient is anaesthetised and receiving mechanical ventilation, when the clinical signs of cerebral dysfunction will be absent. In this situation the diagnostic criteria for ALI/ARDS should then be applied and routine screening for evidence of SIRS, MODS and signs of systemic embolism undertaken (Table II). The use of the term FES should now be restricted to situations in which definite evidence of systemic embolisation can be confirmed by the presence of two of the 'major' triad of respiratory, cutaneous and neurological signs (Table II). In the rare instances when the characteristic petechial rash on the upper torso or cerebral signs occur in isolation, the presence of features of SIRS/MODS should be seen as confirmatory evidence of FES.

Until we have further clarification of the basic pathological processes, it is suggested that future research studies should record measurements of the five groups of parameters shown in Table II.

\section{Controversies in the treatment of fractures in patients at risk of ARDS/FES}

Most of the comparative studies carried out in the last 20 years have shown a reduction in the risk of ARDS/FES after early definitive stabilisation of the fractures, both in patients with isolated fractures ${ }^{42,62-66}$ and in those with injury to multiple systems (Fig. 2). ${ }^{62,63,67-74}$ The protective effect of early surgery has also been demonstrated in children. $^{75,76}$ There is also evidence of a reduction in mortality, the duration of mechanical ventilation, nosocomial infections, thromboembolic disease and the cost of treatment after early stabilisation of the fracture. ${ }^{63,77}$ Most of these studies have examined patients with diaphyseal fractures in the leg in which the standard operative treatment has evolved from the plate fixation to reamed intramedullary nailing.

There are, however, a number of concerns regarding these previous studies, many of which have been small, retrospective or uncontrolled quasi-randomised trials, with considerable potential for confounding and bias from the variation in complexity, site and severity of injury. Recruitment into randomised controlled trials of these injuries is difficult and most studies have enrolled relatively small numbers of patients. It was recently estimated that over 2000 patients would need to be included in any study to examine definitively whether two different methods of treatment of a fracture had significant differences in their rates of pulmonary complications. ${ }^{78}$

During the last 20 years, there have also been significant improvements in the speed of delivery of emergency services, in techniques of resuscitation and the provision of intensive care, which must also have had a significant impact in reducing pulmonary complications. The impact of modern methods of the treatment of fractures has also, perhaps, led to an overstatement of the importance of the musculoskeletal injury in determining the risk of respiratory complications in multiply-injured patients. In most studies, this risk is increased to a much greater extent by the presence of a concomitant chest or head injury, hypovolaemia or the requirement for repeated blood transfusion. $^{34,79-82}$

The wisdom of attempting early definitive surgery for all patients with fractures has been questioned in recent years. Most of the debate has centred on whether there are particular anatomical and physiological patterns of injury which may benefit from either a delay in a definitive operation or the use of alternative techniques to that of reamed nailing. In practice, such injuries seldom occur in isolation without a degree of injury to other body systems. In multiply-injured patients, however, considerable damage to another body system may determine the priorities in initial management and act as a 'modifier' to the ideal treatment which would be recommended for an isolated fracture. It is therefore useful to consider these various patterns of injury.

Patients with fractures and no significant injury to other body systems. The ideal treatment for patients with an isolated fracture without injury to other systems remains early definitive fixation, ideally carried out within 24 hours. Reamed intramedullary nailing is the method of choice for most isolated femoral and tibial fractures. The widespread 


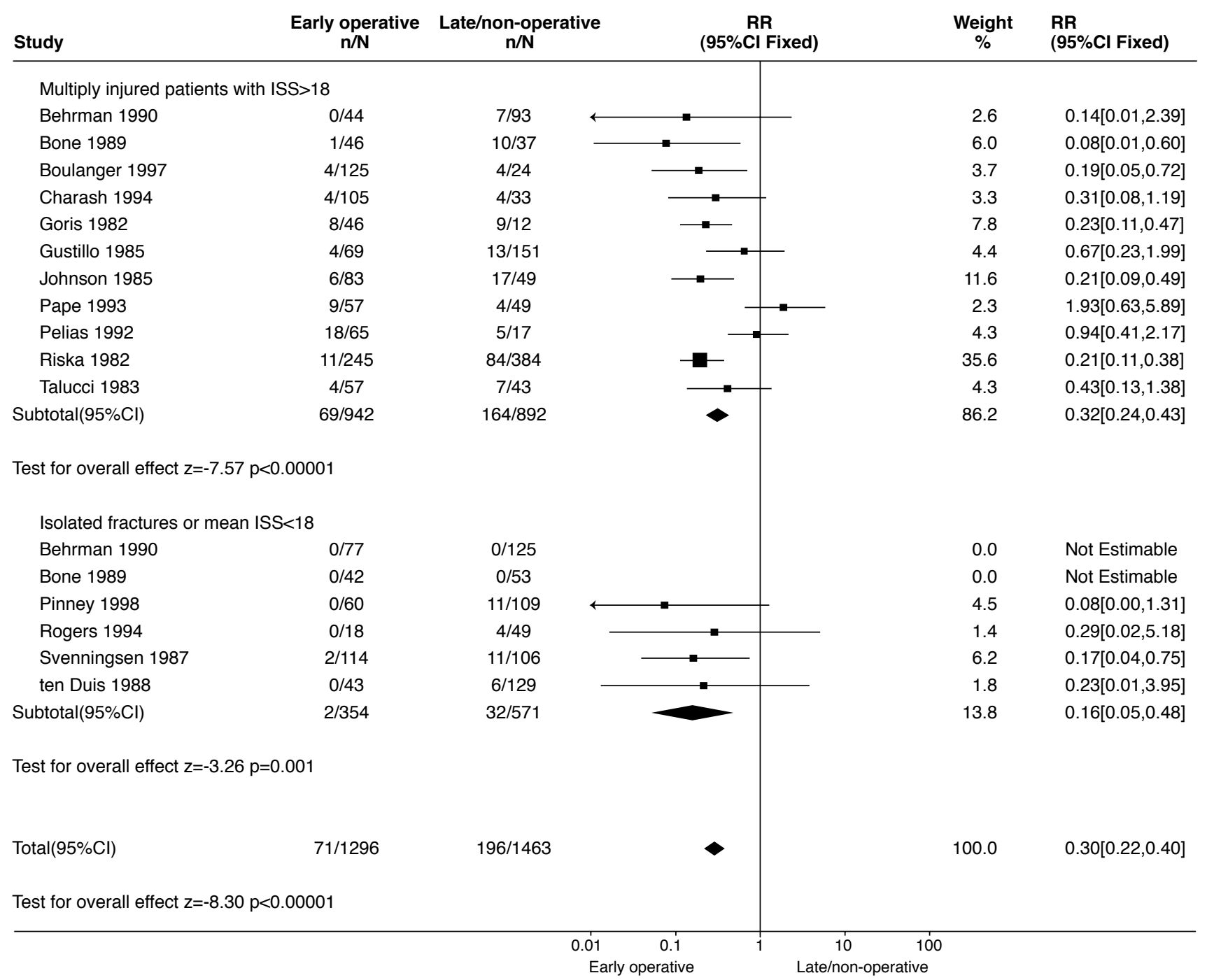

Fig. 2

Summary of the previous English-language studies which have compared the effects of early operative stabilisation of the fracture (usually within 24 hours) with late or non-operative treatment on the incidence of post-traumatic respiratory complications. As ARDS, FES and other more non-specific terms have been variously used to describe refractory hypoxaemia after fracture, these outcome measures are considered together. The figures to the right of the reference show the number of patients with evidence of post-traumatic respiratory complications (n) as a proportion of the total population (N). The analysis is substratified into studies which have examined mulitply-injured patients (with ISS $>18$ ) and those with isolated fractures. The overall relative risk (RR) reduction in post-traumatic respiratory insufficiency is statistically significant, suggesting a $70 \%$ reduction in the rates of pulmonary complication with the use of early fixation $(\mathrm{RR}=0.30,95 \%$ confidence intervals $(\mathrm{CI}) 0.22$ to 0.40$)$.

increase in its use during the last 20 years has not coincided with any substantial escalation in the incidence of FES. Some patients develop this syndrome before stabilisation of their fractures and the use of reamed nailing in this situation often causes concern because it is likely to produce further substantial FE. There is, however, evidence that the use of nailing may actually be protective against FES in this situation.

Patients with pathological fractures treated by nailing and patients with fractures of the hip treated by cemented hemiarthroplasty are at a higher risk of developing a fulminant form of acute FES, either as a result of florid intraoperative FE, or from a pre-existing coagulopathic state. $^{30,84-86}$

\section{The severely injured patient with multiple injuries (ISS >18)}

Patients with physiological instability or occult hypoxial hypoperfusion. In approximately 5\% of fractures of the long bones in the leg, the patient is 'physiologically unstable' after initial resuscitation because of coagulopathy, haemodynamic instability, raised intracranial pressure, vascular damage or injury to a solid organ. ${ }^{87,88}$ The treatment of these life-threatening conditions takes priority over the orthopaedic injuries in the early stages, and the use of external fixation is advocated, dictated by the requirement for rapid temporary stabilisation of the fracture. If these patients survive, they are also at a much higher risk of ARDS within the first week after injury and it is important 
that early revision to definitive fixation is carried out as soon as they are stabilised.

This form of extreme physiological instability is comparatively rare after musculoskeletal trauma. A larger proportion of patients, however, may have clinically occult tissue hypoxia or hypoperfusion, despite an apparently successful initial resuscitation, ${ }^{89,90}$ as has been increasingly recognised with the use of more invasive forms of monitoring. Many of these patients also have evidence of SIRS and concerns have been raised about the safety of early reamed nailing because the procedure may act as a secondary 'hit', which may trigger the development of ARDS. ${ }^{9,19,20,89}$

Modifications to the basic protocol of early reamed nailing have been examined including the use of temporary external fixation until the inflammatory response has settled or resuscitation is complete, ${ }^{88,91}$ the employment of different methods of fixation such as unreamed nails ${ }^{78,92,93}$ or compression plates, ${ }^{94,95}$ or of techniques designed to reduce fat embolisation during reamed nailing including venting, ${ }^{96}$ lavage of the medullary canal $^{86}$ or an altered design of reamer. ${ }^{97}$

As yet, definitive clinical evidence of a beneficial effect from the use of these measures is lacking and the results of experiments in animals are conflicting. ${ }^{31,98-101}$ There is some evidence to suggest that patients who have been incompletely resuscitated have a higher incidence of pulmonary complications when the operation is carried out early, ${ }^{89,102}$ although it is possible that such patients have a greater initial severity of injury, which is responsible for their poor prognosis. ${ }^{103}$ If delayed fixation is used, it is still not clear how long the delay should be, since reliable laboratory markers of the inflammation or occult tissue hypoperfusion are not generally available.

It could be argued that early definitive fixation should be seen as an even higher priority in patients with evidence of SIRS or occult hypoperfusion because of their increased risk of subsequently developing ARDS. Those who develop this complication may be too medically labile to undergo further surgery for some weeks after this initial phase, and prolonged external fixation may then produce a poor functional outcome or substantially complicate later definitive surgery. 104

The patient with a concomitant chest injury. Attention has also focused on the subgroup of multiply-injured patients with chest injuries, typically a pneumothorax, a haemothorax or pulmonary contusion, since the FE produced by reamed nailing may further compromise their impaired pulmonary function. Similar modifications to the management of the fracture to those described above have been suggested to reduce the extent of $\mathrm{FE}$. The available clinical evidence, however, suggests that it is the chest injury which primarily determines whether the patient develops ARDS and not the femoral fracture, ${ }^{67,68,74,82,93,95,105,106}$ since the risk of this complication in patients with an injured chest remains the same, irrespective of whether or not they have an associated femoral fracture (Figs 3a and 3b). This is substantiated by the absence of a significant difference in the risk of ARDS when comparing patients with chest injury alone with those who also have femoral fractures (Fig. 3c).

Although some studies using animal models have suggested that reamed nailing is detrimental in the presence of lung contusion, ${ }^{107,108}$ this has not been supported by others. 109,110

The patient with a concomitant head injury. Some studies have suggested that early definitive stabilisation of the fractures in patients with a concomitant head injury is safe ${ }^{111}$ or may actually reduce the risk of pulmonary complications, ${ }^{112}$ while others have indicated that early nailing may be deleterious. ${ }^{113}$ It has also been suggested that the timing of fixation of the fracture is less important than the severity of the head injury in determining the risk of ARDS ${ }^{114}$ and that surgery is best carried out after the patient has been fully resuscitated. ${ }^{115}$ There are also theoretical concerns regarding the cerebral FE produced during nailing, which may compromise neurological recovery. Most cerebral FE, however, appears to occur at the time of fracture and is not necessarily produced during its stabilisation. ${ }^{60}$

Other injury combinations. Patients with multiple fractures of long bones are at a greater risk of ARDS than those with single fractures, although this may be because they also tend to have more severe injuries to other body systems. 116 Although there is little supportive clinical evidence, it is probable that patients with musculoskeletal injury and concomitant abdominal, pelvic, spinal or maxillofacial trauma and those with burns have a higher risk of developing respiratory complications.

Overview of the current treatment of fractures. In addition to the considerable variation in the severity and distribution of injury, patients respond differently to it because of the variation in their immune and physiological status. It is difficult to be prescriptive in the orthopaedic management and a flexible approach is likely to be more successful than rigid adherence to a particular technique or protocol. In general terms, however, the more severely injured patient (with ISS >18) with physiological instability, requires temporary methods of fixation until this has been corrected, when definitive fixation can be carried out. For most patients, fractures are best stabilised at an early stage after initial resuscitation. Reamed nailing is the best method of fixation for fractures of long bones in the leg, combined with other techniques to stabilise associated pelvic, spinal, metaphyseal and intra-articular fractures. As yet, there is no convincing clinical evidence to support the routine use of alternative strategies in the presence of occult hypoperfusion or SIRS, chest or head injury or multiple fractures of long bones.

\section{Current management of established ARDS and FES}

The mainstay of treatment for the patients who develop these complications remains largely supportive. Admin- 


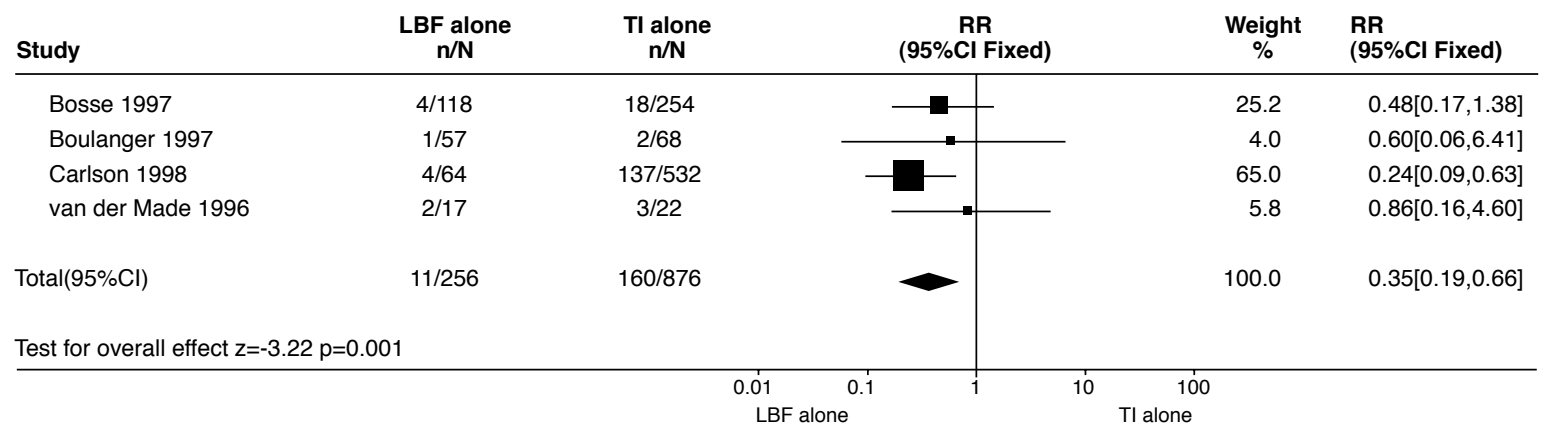

Fig. 3a

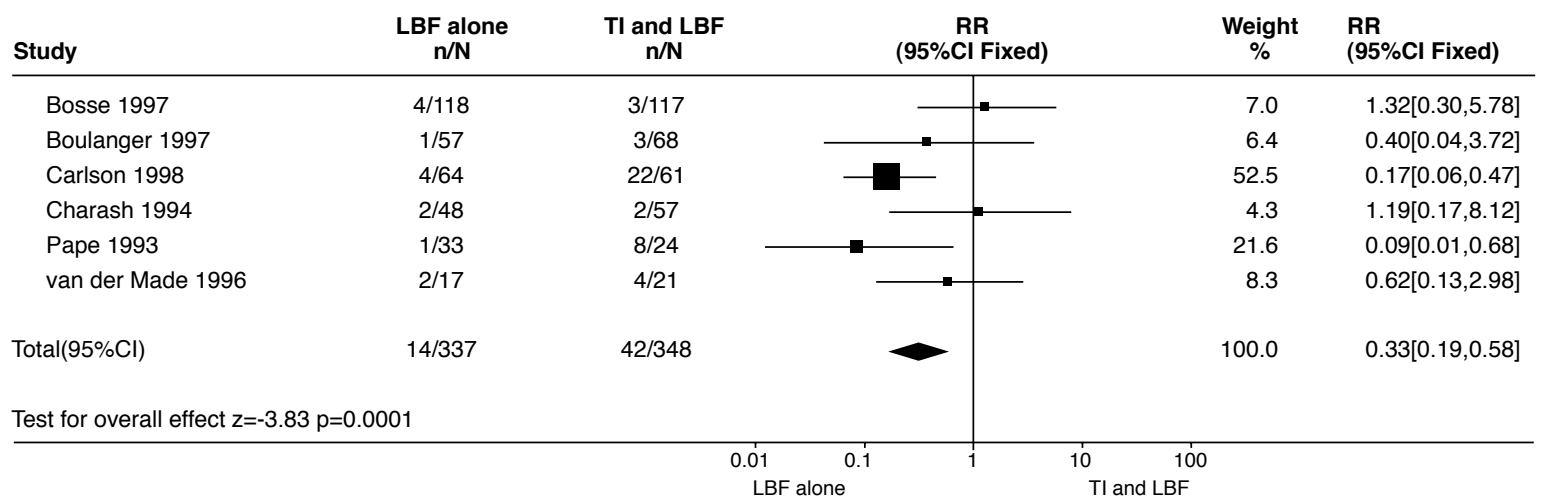

Fig. $3 b$

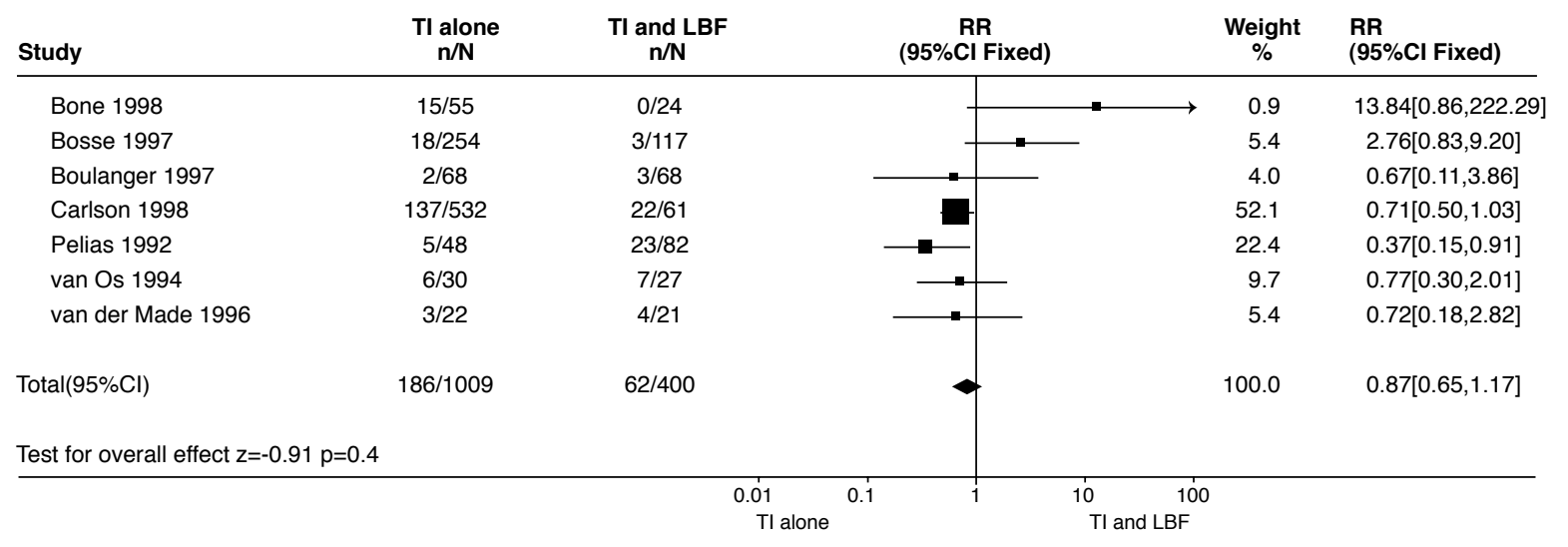

Fig. 3c

Summary of the previous English-language studies which have examined the effects of a chest injury (TI) and/or fracture of a long bone treated by nailing (LBF) on the incidence of post-traumatic respiratory complications in multiply-injured patients. The data are displayed as in Figure 2. The analysis is stratified to compare the incidence of respiratory complications in patients with chest injury alone with those with fracture of a long bone alone (a), fracture of a long bone alone with concomitant chest injury and fracture of a long bone (b), and chest injury alone with concomitant chest injury and fracture of a long bone. (c) Patients with chest injury have a significantly increased risk of pulmonary complications, irrespective of whether they have a concomitant fracture of a long bone $(\mathrm{RR}=0.33, \mathrm{~b})$ or not $(\mathrm{RR}=0.35$, a). There is no significant difference in risk between patients with chest injury alone and those with combined chest and fractures of a long bone $(R R=0.87, p$ value not significant $(c))$.

istration of adequate humidified oxygen is titrated against the patient's needs by monitoring arterial blood gas levels, together with fluid replacement and physiotherapy to the chest to minimise the risk of secondary infection. In the patient who is not managing to maintain adequate oxygenation or who is becoming 'tired' beause of prolonged air-hunger, mechanical ventilation may be required, although a trial of application of constant positive airways pressure (CPAP) to a tight-fitting mask may obviate this. If mechanical ventilation is used, the hypoxaemia is addressed by manipulating the concentration of inspired oxygen and using positive end-expiratory pressures. Antibiotics may be required for secondary infection and tracheostomy and nutritional support may be needed if prolonged ventilation is necessary.

Specific methods of treatment which have been subjected 
to randomised trials include the administration of corticosteroids, ${ }^{117}$ heparin, ${ }^{118}$ dextran ${ }^{119}$ and anticytokines. ${ }^{8}$ Although some of the results have been encouraging, none of these interventions has been widely adopted because each has a substantial risk of harmful and occasionally catastrophic side-effects.

\section{Prognosis}

The mortality in both of these conditions remains considerable, although there is evidence that the overall survival has improved in recent years. ${ }^{120}$ It is generally considered that the prognosis from ARDS is worse, with an expected mortality in the vicinity of 50\%, although most studies have been carried out in intensive-care units on patients with severe trauma to multiple systems in whom the death rate is expected to be higher. ${ }^{10}$ The cause of death in approximately one-third of patients is due to other injuries, especially to the head. In the remainder, death is usually either as a result of overwhelming secondary sepsis or MODS. The mortality from FES is usually reported as between 5\% and $15 \%,{ }^{43}$ but it may be as high as $36 \%$ in patients who require mechanical ventilation. ${ }^{121}$

There is little information on the residual respiratory morbidity from the sequelae of pulmonary involvement in ARDS and FES. Patients with FES may have persistent neurological deficits, ${ }^{48,58}$ although spontaneous recovery may occur gradually over many months. Severe hepatic and renal involvement in both ARDS and FES may result in permanent impairment in the function of these organs.

\section{Summary}

Initial diligent resuscitation of the multiply-injured patient, with early fixation of the major orthopaedic injuries, has significantly reduced the incidence of post-traumatic respiratory complications from the unacceptably high levels which were seen 20 years ago. With these improvements we may be entering an era in which the risk of these complications is independent of the orthopaedic injury and is determined largely by the severity of injury to other body systems or by the immune and physiological status of the patient. Substantive proof of any beneficial effect from modification of the timing and technique of fracture stabilisation will be difficult to achieve without large multicentre randomised trials. It is conceivable that these interventions have a negligible effect on outcome or may actually be detrimental.

Unravelling the basic molecular and cellular pathogenic processes of ARDS and FES will lead to improved therapeutic strategies for the treatment of this condition. For the present, however, the evidence suggests that expedient and appropriate early treatment of fractures in most instances protects against the development of post-traumatic respiratory insufficiency. Currently, the best and most effective therapeutic tool of the practising orthopaedic/trauma surgeon is prevention.

\section{References}

1. Riseborough EJ, Herndon JH. Alterations in pulmonary function, coagulation and fat metabolism in patients with fractures of the lower limbs. Clin Orthop 1976;115:248-67.

2. Chan KM, Tham KT, Chiu HS, Chow YN, Leung PC. Posttraumatic fat embolism: its clinical and subclinical presentations. $J$ Trauma 1984;24:45-9.

3. Moed BR, Boyd DW, Andring RE. Clinically inapparent hypoxemia after skeletal injury: the use of the pulse oximeter as a screening method. Clin Orthop 1993:269-73.

4. Zenker FA. Beiträge zur normalen and pathologischen Anatomie der Lunge. Dresden: J Braunsdorf, 1862.

5. Ashbaugh DG, Bigelow DB, Petty TL, Levine BE. Acute respiratory distress in adults. Lancet 1967;2:319-23.

6. Giannoudis PV, Smith RM, Banks RE, et al. Stimulation of inflammatory markers after blunt trauma. $\mathrm{Br} J \quad$ Surg 1998;85:986-90.

7. Faist E, Schinkel C, Zimmer S. Update on the mechanisms of immune suppression of injury and immune modulation. World J Surg 1996;20:454-9.

8. Bone RC. Imunologic dissonance: a continuing evolution in our understanding of the systemic inflammatory response syndrome (SIRS) and the multiple organ dysfunction syndrome (MODS). Ann Int Med 1996;125:680-7.

9. Moore EE. Synergy of bone fracture, soft tissue disruption and haemorrhagic shock in the genesis of postinjury immunochaos: the pathway to multiple organ failure. Crit Care Med 1998;26:1305-6.

10. Montgomery AB, Stager MA, Carrico CJ, Hudson LD. Causes of mortality in patients with the adult respiratory distress syndrome. Am Rev Respir Dis 1985;132:485-9.

11. Bone RC, Balk RA, Cerra FB, et al. ACCP/SCCM consensus conference: definitions for sepsis and organ failure and guidelines for the use of innovative therapies in sepsis. Crit Care Med 1991;101:1644-55.

12. Pugin J, Verghese G, Widmer M-C, Matthay MA. The alveolar space is the site of intense inflammatory and profibroblastic reactions in the early phase of the adult respiratory distress syndrome. Crit Care Med 1999;27:304-12.

13. Chollet-Martin S, Jourdain B, Tuder R. Interactions between neutrophils and cytokines in blood and alveolar spaces during ARDS. Am J Resp Crit Care Med 1996;154:594-601.

14. Windsor AC, Mullen PG, Fowler AA. Role of the neutrophil in the adult respiratory distress syndrome. Br J Surg 2001;80:10-7.

15. Robinson CM, Ludlam CA, Ray DC, Swann DG, Christie J. The coagulative and cardiorespiratory responses to reamed intramedullary nailing of isolated fractures. J Bone Joint Surg [Br] 2001;in press.

16. Hasleton PS. Adult respiratory distress syndrome: a review. Histopathology 1983;7:307-14.

17. Dantzker DR, Brook CJ, Dehart P, et al. Ventilation-perfusion relationships in the adult respiratory distress syndrome. Am Rev Respir Dis 1979;120:1039-42.

18. Moore FA, Moore EE. Evolving concepts in the pathogenesis of post-injury multiple organ failure. Surg Clin North Am 1995;75:257-77.

19. Waydhas C, Nast-Kolb D, Trupka A, et al. Posttraumatic inflammatory response, secondary operations, and late multiple organ failure. J Trauma 1996;40:624-31.

20. Giannoudis PV, Smith RM, Bellamy MC, et al. Stimulation of the inflammatory system by reamed and unreamed nailing of femoral fractures: an analysis of the second hit. J Bone Joint Surg [Br] 1999;81-B:356-61.

21. Sevitt S. The significance of fat embolism. Brit J Hosp Med 1973:786-93.

22. Byrick RJ, Mullen JB, Mazer CD, Guest CB. Transpulmonary systemic fat embolism: studies in mongrel dogs after cemented arthroplasty. Am J Resp Crit Care Med, 1994;150:1416-22.

23. Pell AC, Hughes D, Keating $\mathbf{J}$, et al. Brief report: fulminating fat embolism syndrome caused by paradoxical embolism through a patent foramen ovale (see comments). $N$ Engl J Med 1993;329:926-9.

24. King EG, Weily HS, Genton E, Ashbaugh DG. Consumption coagulopathy in the canine oleic acid model of fat embolism. Surgery 1971;69:533-41. 
25. Parker FB, Wax SD, Kusajima K, Webb WR. Hemodynamic and pathological findings in experimental fat embolism. Arch Surg 1974;108:70-4.

26. Peltier LF, Adler F, Lai S-P. Fat embolism: the significance of an elevated serum lipase after trauma to bone. Am J Surg 1960;99:821-6.

27. Saldeen T. Fat embolism and signs of intravascular coagulation in a posttraumatic autopsy material. J Trauma 1970;10:273-86.

28. Gitin TA, Seidel T, Cera PJ, Glidewel OJ, Smith JL. Pulmonary microvascular fat: the significance? Crit Care Med 1993;21:673-7.

29. Wenda K, Henrichs KJ, Biegler M, Erbel R. Recording of bonemarrow embolism during intramedullary nailing of the femur by transoesophageal echocardiography. Unfallchirurgie 1989;15:73-6.

30. Christie J, Robinson CM, Pell ACH, McBirnie J, Burnett R. Transcardiac echocardiography during invasive intramedullary procedures. J Bone Joint Surg [Br] 1995;77-B:450-5.

31. Schemitsch EH, Jain R, Turchin DC, et al. Pulmonary effects of fixation of a fracture with a plate compared with intramedullary nailing: a canine model of fat embolism and fracture fixation. $J$ Bone Joint Surg [Am] 1997;79-A:984-96.

32. Schemitsch EH, Turchin DG, Anderson GI, et al. Pulmonary and systemic fat embolization after medullary canal pressurization: a hemodynamic and histologic investigation in the dog. J Trauma 1998;45:738-42.

33. Bone RC. Pulmonary microvascular fat in lung injury: an epiphenomenon? Crit Care Med 1993;21:644.

34. Pepe EP, Potkin RT, Reus DH, Hudson LD, Carrico CJ. Clinical predictors of the adult respiratory distress syndrome. Am J Surg 1982;144:124-30.

35. Moore FA, Moore EE, Read RA. Postinjury multiple organ failure: role of extrathoracic injury and sepsis in adult respiratory distress syndrome. New Horizons 1993;1:538-49.

36. Avikainen V, Willman K, Rokkanen P. Stress hormones, lipids, and factors of hemostasis in trauma patients with and without fat embolism syndrome: a comparative study at least one year after severe trauma. J Trauma 1980;20:148-53.

37. Nawroth PP, Stern DM. Modulation of endothelial cell hemostatic properties by tumour necrosis factor. J Exper Med 1986;163:740-5.

38. Hulman G. The pathogenesis of fat embolism. $J$ Pathol 1995;176:3-9.

39. Coughlin SR. Thrombin signalling and protease-activated receptors. Nature 2000;407:258-64.

40. Fowler AA, Hamman RF, Good JT, et al. Adult respiratory distress syndrome: risk with common predispositions. Ann Int Med 1983;98:539-97.

41. Pepe PE, Thomas RG, Stager MA, Hudson LD, Carrico CJ. Early prediction of the adult respiratory distress syndrome by a simple scoring method. Ann Emerg Med 1983;12:749-55.

42. ten Duis HJ, Nijsten MWN, Klasen HJ, Binnendijk B. Fat embolism in patients with an isolated fracture of the femoral shaft. $J$ Trauma 1988;28:383-90.

43. Bulger EM, Smith DG, Maier RV, Jurkovich GJ. Fat embolism syndrome: a 10-year review. Arch Surg 1997;132:435-9.

44. Riska BE, Myllynen P. Fat embolus in patients with multiple injuries. J Trauma 1982;22:891-4.

45. Rokkanen P, Lahdensuu M, Kataja J, Julkunen H. The syndrome of fat embolism: analysis of thirty consecutive cases compared to trauma patients with similar injuries. J Trauma 1970;10:299-306.

46. Mudd KL, Hunt A, Matherly RC, et al. Analysis of pulmonary fat embolism in blunt force fatalities. J Trauma 2000;48:711-5.

47. Gurd AR. Fat embolism: an aid to diagnosis. J Bone Joint Surg [Br] 1970;52-B:732-37.

48. Gurd AR, Wilson RI. The fat embolism syndrome. $J$ Bone Joint Surg [Br] 1974;56-B:408-16.

49. Schonfeld SA, Ploysongsang Y, DiLisio R, et al. Fat embolism prophylaxis with corticosteroids: a prospective study in high-risk patients. Ann Intern Med 1983;99:438-43.

50. Lindeque BGP, Schoeman HS, Domisse GF, Boeyens MC, Vlok AL. Fat embolism and the fat embolism syndrome: a double-blind therapeutic study. J Bone Joint Surg [Br] 1987;69-B:128-31.

51. Bone RC, Maunder R, Slotman G, et al. An early test of survival in patients with the adult respiratory syndrome: the $\mathrm{PaO}_{2} / \mathrm{FiO}_{2}$ ratio and its differential response to conventional therapy. Chest 1989;96:849-51.
52. Bernard GR, Artigas A, Brigham KL, et al. The AmericanEuropean consensus conference on ARDS: definitions, mechanisms, relevant outcomes and clinical trial co-ordination. Am J Resp Crit Care Med 1994;149:818-24.

53. Donnelly SC, Strieter RM, Kunkel SL, et al. Interleukin- 8 and development of adult respiratory distress syndrome in at-risk patient groups. Lancet 1993;341:643-7.

54. Chastre J, Fagon JY, Soler $\mathbf{P}$, et al. Bronchoalveolar lavage for rapid diagnosis of the fat embolism syndrome in trauma patients. Ann Intern Med 1990;113:583-8.

55. Masson RG, Ruggieri J. Pulmonary microvascular cytology: a new diagnostic application of the pulmonary artery catheter. Chest 1985;88:908-14.

56. Marshall JC, Cook DJ, Christou NV, et al. Multiple organ dysfunction score: a reliable descriptor of a complex clinical outcome. Crit Care Med 1995;23:1638-52.

57. Le Gall JR, Klar J, Lemeshow S, et al. The logistic organ dysfunction system: a new way to assess organ dysfunction in the intensive care unit: ICU scoring group. JAMA 1996;276:802-10.

58. Jacobson DM, Terrence CF, Reinmuth OM. The neurologic manifestations of fat embolism. Neurology 1986;36:847-51.

59. Stoeger A, Daniaux M, Felber S, et al. MRI findings in cerebral fat embolism. Eur Radiol 1998;8:1590-3.

60. Zych GA, Forteza A, Koch S, Campo I, Hutson JJ. Detection of cerebral fat embolism in patients with femoral fractures. Procs 16th Annual Meeting of the American Orthopaedic Trauma Association, 2000.

61. Baker SP, O'Neill B, Hadden W Jr, Long WB. The injury severity score: a method for describing patients with multiple injuries and evaluating emergency care. J Trauma 1974;14:187-96.

62. Behrman SW, Fabian TC, Kudsk KA, Taylor JC. Improved outcome with femur fractures: early versus delayed fixation. $J$ Trauma 1990;30:792-8.

63. Bone LB, Johnson KD, Weigelt J, Scheinberg R. Early versus delayed stabilisation of femoral fractures: a prospective randomised study. J Bone Joint Surg [Am] 1989;71-A:336-40.

64. Pinney SJ, Keating JF, Meek RN. Fat embolism syndrome in isolated femoral fractures: does timing of nailing influence incidence? Injury 1998;29:131-3.

65. Rogers FB, Shackford SR, Vane DW, Kaups KL, Harris F. Prompt fixation of isolated femur fractures in a rural trauma center: a study examining the timing of fixation and resource allocation. $J$ Trauma 1994;36:774-7.

66. Svenningsen S, Nesse O, Finsen V, Hole A, Benum P. Prevention of fat embolism syndrome in patients with femoral fractures: immediate of delayed operative fixation. Ann Chirurg Gynaecol 1987;76:163-6.

67. Boulanger BR, Stephen D, Brenneman FD. Thoracic trauma and early intramedullary nailing of femur fractures: are we doing harm? J Trauma 1997;43:24-8.

68. Charash WE, Fabian TC, Croce MA. Delayed surgical fixation of femur fractures is a risk factor for pulmonary failure independent of thoracic trauma. J Trauma 1994;37:667-72.

69. Goris RJA, Gimbrère JST, van Niekerk JLM, Schoots JF, Booy LHD. Early osteosynthesis and prophylactic mechanical ventilation in the multitrauma patient. J Trauma 1982;22:895-903.

70. Johnson KD, Cadambi A, Seibert GB. Incidence of adult respiratory distress syndrome in patients with multiple musculoskeletal injuries: effect of early operative stabilization of fractures. $J$ Trauma 1985;25:375-84.

71. Pelias ME, Townsend MC, Flanebaum L. Long bone fractures predispose to pulmonary dysfunction in blunt chest trauma despite early operative fixation. Surgery 1992;111:576-9.

72. Riska EB, Myllynen P. Fat embolism in patients with multiple injuries. J Trauma 1982;22:891-4.

73. Talucci RC, Manning J, Lampard S, Bach A, Carrico CJ. Early intramedullary nailing of femoral shaft fractures: a cause of fat embolism syndrome. Am J Surg 1983;146:107-11.

74. Pape HC, Auf'm'Kolk M, Paffrath T, et al. Primary intramedullary femur fixation in multiple trauma patients with associated lung contusion: a cause of post-traumatic ARDS? J Trauma 1993;34:540-8.

75. Hedequist D, Starr AJ, Wilson P, Walker J. Early versus delayed stabilization of pediatric femur fractures: analysis of 387 patients. $J$ Orthop Trauma 1999;13:490-3. 
76. Tolo VT. Orthopaedic treatment of fractures of the long bones and pelvis in children who have multiple injuries. Instr Course Lect 2000;49:415-23.

77. Seibel R, Laduca J, Hassett JM, et al. Blunt multiple trauma (1SS36), femur traction and a pulmonary failure - septic state. Ann Surg 1985;202:283-95.

78. Powell JN. A prospective, randomised trial comparing reamed and unreamed intramedullary nailing: an analysis of pulmonary complications. Procs American Orthopaedic Trauma Association Meeting, San Antonio, 2000:90-1.

79. Phillips TF, Soulier G, Wilson RF. Outcome of massive transfusion exceeding two blood volumes in trauma and emergency surgery. $J$ Trauma 1987;27:903-10.

80. Hoyt DB, Simons BK, Winchell RJ, et al. A risk analysis of pulmonary complications following major trauma. J Trauma 1993;35:524-31.

81. Bratton SL, Davis RL. Acute lung injury in isolated traumatic brain injury. Neurosurgery 1997;40:707-12.

82. Ziran BH, Le T, Zhou H, Fallon W, Wilber JH. The impact of the quantity of skeletal injury on mortality and pulmonary morbidity. $J$ Trauma 1997;43:916-21.

83. Riska EB, von Bonsdorff H, Hakkinen S, et al. Prevention of fat embolism by early internal fixation of fractures in patients with multiple injuries. Injury 1974;8:110-6.

84. Kerr PS, Jackson M, Atkins M. Cardiac arrest during intramedullary nailing for femoral metastases. J Bone Joint Surg [Br] 1993;75-B:972-3.

85. Christie J, Burnett R, Potts HR, Pell ACH. Echocardiography of transatrial embolism during cemented and uncemented hemiarthroplasty of the hip. J Bone Joint Surg [Br] 1994;76-B:409-12.

86. Christie J, Robinson CM, Singer B, Ray DC. Medullary lavage reduces embolic phenomena and cardiopulmonary changes during cemented hemiarthroplasty. J Bone Joint Surg [Br] 1995;77-B:4569.

87. Scalea TM, Boswell SA, Scott JD, et al. External fixation as a bridge to intramedullary nailing for patients with multiple injuries and with femur fractures: damage control orthopedics. J Trauma 2000;48:613-21.

88. Nowotarski PJ, Turen CH, Brumback RJ, Scarboro JM. Conversion of external fixation to intramedullary nailing from fractures of the shaft of the femur in mulitply injured patients. J Bone Joint Surg [Am] 2000;82-A:781-8.

89. Crowl AC, Young JS, Kahler DM, et al. Occult hypoperfusion is associated with increased morbidity in patients undergoing early femur fracture fixation. J Trauma 2000;48:260-7.

90. Rixen D, Raum M, Bouillon B, Lefering R, Neugebauer E. Base deficit development and its prognostic significance in posttrauma critical illness: an analysis by the trauma registry of the Deutsche Gesellschaft fur unfallchirurgie. Shock 2001;15:83-9.

91. Friedl HP, Stocker R, Czermak B, Schmal H, Trentz O. Primary fixation and delayed nailing of long bone fractures in severe trauma. Techniques in Orthopaedics 1996;11:59-66.

92. Pape HC, Regel G, Dwenger A, et al. Influences of differen methods of intramedullary femoral nailing on lung function in patients with multiple trauma. J Trauma 1993;35:709-16.

93. Carlson DA, Rodman GH, Kaehr D, Hage J, Misinski M. Femur fractures in chest-injured patients: is reaming contraindicated? $J$ Orthop Trauma 1998;12:164-8.

94. Bosse MJ, MacKenzie EJ, Riemer BL, et al. Adult respiratory distress syndrome, pneumonia, and mortality following thoracic injury and a femoral fracture treated either with intramedullary nailing with reaming or with a plate: a comparative study. $J$ Bone Joint Surg [Am] 1997;79-A:799-809.

95. Bone LB, Anders MJ, Rohrbacher BJ. Treatment of femoral fractures in the multiply injured patient with thoracic injury. Clin Orthop 1998;347:57-61.

96. Martin R, Leighton RK, Petrie D, Ikejiani C, Smyth B. Effect of proximal and distal venting during intramedullary nailing. Clin Orthop 1996;332:80-9.

97. Muller CA, Frigg R, Pfister U. Can modifications to reamer and flexible shaft design decrease intramedullary pressure during reaming? An experimental investigation. Techniques in Orthopaedics $1996 ; 11: 18-27$
98. Pape HC, Dwenger A, Regel G, Remmers D, Tscherne H. Intramedullary femoral nailing in sheep: does severe injury predispose to pulmonary dysfunction. Eur J Surg 1995;161:163-71.

99. Heim D, Regazzoni P, Tsakiris DA, et al. Intramedullary nailing and pulmonary embolism: does unreamed nailing prevent embolization? An in-vivo study in rabbits. J Trauma 1995;38:899-906.

100. Neudeck F, Wozasek GE, Obertacke U, Thurnher M, Schlag G. Nailing versus plating in thoracic trauma: an experimental study in sheep. J Trauma 1996;40:980-4.

101. Pape HC, Bartels M, Pohlemann T, et al. Coagulatory response after femoral instrumentation after severe trauma in sheep. J Trauma 1998;45:720-8

102. Reynolds MA, Richardson JD, Spain DA, et al. Is the timing of fracture fixation important for the patient with multiple trauma? Ann Surg 1995;222:470-8.

103. Henao FJ, Daes JE, Dennis RJ. Risk factors for multiorgan failure: a case-control study. J Trauma 1991;31:74-80.

104. Murphy CP, D'Ambrosia RD, Dabezies EJ, et al. Complex femur fractures: treatment with the Wagner external fixation device or the Grosse-Kempf interlocking nail. J Trauma 1988;28:1553-61.

105. van Os JP, Roumen RM, Schoots FJ, Heystraten FM, Goris RJ. Is early osteosynthesis safe in multiple trauma patients with severe thoracic trauma and pulmonary contusion. J Trauma 1994;36:495-8.

106. van der Made WJ, Smit EJM, van Luyt PA, van Vugt AB. Intramedullary femoral osteosynthesis: an additional cause of ARDS in multiply injured patients. Injury 1996;27:391-3.

107. Pape H-C, Dwenger A, Regel G, et al. Pulmonary damage after intramedullary femoral nailing in traumatized sheep - is there an effect from different nailing methods? J Trauma 1992;33:574-81.

108. Elmaraghy AW, Aksenov S, Byrick RJ, Richards RR, Schemitsch EH.l Pathophysiological effect of fat embolism in a canine model of pulmonary contusion. J Bone Joint Surg [Am] 1999;81-A:1155-64.

109. Duwelius PJ, Huckfeldt R, Mullins RJ, et al. The effects of femoral intramedullary reaming on pulmonary function in a sheep lung model. J Bone Joint Surg [Am] 1997;79-A:194-202.

110. Wolinsky PR, Banit D, Parker RE, et al. Reamed intramedullary femoral nailing after induction of an 'ARDS-like' state in sheep: effect on clinically applicable markers of pulmonary function. $J$ Orthop Trauma 1998;12:169-75; discussion 175-6.

111. Scalea TM, Scott JD, Brumback RJ, et al. Early fracture fixation may be 'just fine' after head injury: no difference in central nervous system outcomes. J Trauma 1999;46:839-46.

112. Starr AJ, Hunt JL, Chason DP, Reinert CM, Walker J. Treatment of femur fracture with associated head injury. J Orthop Trauma $1998 ; 12: 38-45$

113. Jaicks RR, Cohn SM, Moller BA. Early fracture fixation may be deleterious after head injury. J Trauma 1997;42:1-5.

114. Poole GV, Miller JD, Agnew SG, Griswold JA. Lower extremity fracture fixation in head-injured patients. J Trauma 1992;32:654-9.

115. Townsend RN, Lheureau T, Protech J, Riemer B, Simon D. Timing fracture repair in patients with severe brain injury (Glasgow Coma Scale score <9). J Trauma 1998;44:977-82.

116. Copeland CE, Mitchell KA, Brumback RJ, Gens DR, Burgess AR. Mortality in patients with bilateral femoral fractures. J Orthop Trauma 1998;12:315-9.

117. Bernard GR, Luce JM, Sprung CL, et al. High-dose corticosteroids in patients with the adult respiratory distress syndrome. New Engl J Med 1987;317:1565-70.

118. Sage RH, Tudor RW. Treatment of fat embolism with heparin. $\mathrm{Br}$ Med J 1958;I:1160-1.

119. Bergentz S-E. Indications for the use of low viscous dextran in surgery. Acta Chir Scand 1961;122:343-57.

120. Milberg JA, Davis DR, Steinberg KP, Hudson LD. Improved survival of patients with the acute respiratory distress syndrome (ARDS): 1983-1993. JAMA 1995;273:306-9.

121. Wildsmith JA, Masson AH. Severe fat embolism: a review of 24 cases. Scott Med J 1978;23:141-8. 